\title{
SHAKEDOWN BEHAVIOUR OF COMPOSITE CYLINDERS WITH CROSS HOLE
}

\author{
Haofeng Chen \\ Department of Mechanical Engineering \\ University of Strathclyde \\ Glasgow, Scotland, UK
}

\author{
Tianbai Li \\ Department of Mechanical Engineering \\ University of Strathclyde \\ Glasgow, Scotland, UK
}

\author{
Weihang Chen \\ Department of Mechanical Engineering \\ University of Strathclyde \\ Glasgow, Scotland, UK
}

\author{
James Ure \\ Department of Mechanical Engineering \\ University of Strathclyde \\ Glasgow, Scotland, UK
}

\begin{abstract}
In this study, both the lower and upper bound shakedown limits of a closed-end composite cylinder with or without a cross hole subject to constant internal pressure and a cyclic thermal gradient are calculated by the Linear Matching Method (LMM). Convergence for upper and lower bound shakedown limit of the composite cylinders is sought and shakedown limit interaction diagrams of the numerical examples identifying the regions of reverse plastic limit and ratchet limit are presented. The effects of temperature-dependent yield stress, materials discontinuities, composite cylinder thickness and the existence of cross hole on the shakedown limits are discussed for different geometry parameters. Finally, a safety shakedown envelope is created by formulating the shakedown limit results of different composite material and cylinder thickness ratios with different cross hole sizes.
\end{abstract}

Keywords: lower and upper bound, shakedown, linear matching method, composite cylinder

\section{INTRODUCTION}

Materials have largely been kept responsible for performance improvements in many areas of structures technology. The continuous development of computational structures technology and the advanced composite materials has improved structural performance, reduced operational risk, and shortened production time [1]. On the other hand one of the most important reasons for using composite materials is the reduction of weight [2].

With the achievements in aerospace industry, the strengthto-weight ratio of engineering components has become a very important design criterion since a high strength-to-weight ratio results in a better performance and greater shear strength. The lower weight results in lower fuel consumption and emissions.

Strength-to-weight ratio can be increased by taking materials beyond the elastic limit and defining limits of allowable accumulated plastic strain. This approach can be applied for the design of composite pressure cylinder subjected to cyclic mechanical and thermal loads. The investigation of the elastic and elastic-plastic behaviour of uniform cylinder under constant internal pressure and cyclic thermal loads with cross hole are presented by the well-known Bree-like diagram in [3] and [4].

The local stress concentration is redistributed around the material boundaries for composite cylinders under cyclic thermal loads. This changes the fatigue life and elastic shakedown limits of the cylinder. The elastic shakedown limit is the highest cyclical load that shakes down to an elastic response in the first few cycles of load. When the elastic shakedown limit is exceeded, the cylinder may experience either plastic shakedown or ratchetting. In many applications, it is allowable for a structure to be within the elastic shakedown load limit, but plastic shakedown or alternating plasticity, under which local low-cycle fatigue failure mode occurs, and ratchetting that ultimately leads to incremental plastic collapse, are not permitted. Consequently the shakedown limit is a particularly important design condition to the pressure cylinder. Such design techniques require an understanding of the elasticplastic behaviour of structure. The elastic-plastic response of a material is load path dependent and most commonly simulated by incremental Finite Element Analysis (FEA). This allows investigation of any type of load cycle but also requires detailed load history and involves significant computer effort.

To avoid such difficulties, direct methods are incorporated into finite element analysis in order to evaluate the shakedown limit. The material model is assumed to be elastic perfectly plastic, and the load domain containing all possible load paths eliminates the need to know a precise load history. Such methods include mathematical programming methods [5-7], the Generalized Local Stress Strain (GLOSS) r-node method [8], the Elastic Compensation Method (ECM) $[9,10]$, and the Linear Matching Method (LMM) [11-15]. Among these direct methods, the LMM is considered to be the most adaptable method to practical engineering applications that involve complex cyclic thermo-mechanical load conditions. Other direct methods require specific programs that are not available or supported commercially, or have difficulties to effectively analyze complex engineering structures. The stable and accurate results of LMM on shakedown analysis have been confirmed in many industrial applications, for example, the 
problem of the defective pipeline [11] and a super heater outlet penetration tube plate [20].

In this paper, the linear matching method is applied for shakedown analysis of a composite cylinder with cross holes subjected to constant internal pressure and cyclic thermal loads. The Bree-like shakedown limit diagrams of composite cylinder are plotted for different composite material and thickness ratios with and without cross holes. Three cross-hole sizes are considered, all relatively small in comparison with the other cylinder dimensions. The objective of the investigation is to formulate a safety shakedown limit region for industrial purposes using the calculated shakedown limit results of different composite material ratio and cylinder thickness ratio with different cross hole sizes.

\section{NUMERICAL PROCEDURES}

The basic assumption of the analysis of shakedown is that the material is considered to be isotropic, elastic-perfectly plastic and satisfying the von Mises yield condition. In order to solve problems in practice with high temperature effects, the yield stress of the material is considered to be temperaturedependent. This dependence is implemented at Gauss points and related to every loading vertex of loading domain. Let a body subjected to cyclic history of varying temperature $\lambda \theta\left(x_{i}, t\right)$ within the volume of the structure and surface loads $\lambda P_{i}\left(x_{i}, t\right)$ acting over part of the structure's surface $S_{T}$ be considered. The variation is considered to be over a typical cycle $0 \leq t \leq \Delta t$. Here $\lambda$ denotes a load parameter, allowing a whole class of loading histories to be taken into account. On the remainder of the surface $S$, denoted $S_{u}$, the displacement is $u_{i}=0$. Corresponding to these loading histories, a linear elastic solution history is obtained;

$$
\lambda \hat{\sigma}_{i j}=\lambda \hat{\sigma}_{i j}^{\theta}+\lambda \hat{\sigma}_{i j}^{P}
$$

where $\hat{\sigma}_{i j}^{\theta}$ and $\hat{\sigma}_{i j}^{P}$ are the elastic solutions corresponding to $\theta\left(x_{i}, t\right)$ and $P_{i}\left(x_{i}, t\right)$, respectively.

For shakedown cyclic problems the cyclic stress history, during a typical cycle $0 \leq t \leq \Delta t$, irrespective of material properties is given by

$$
\sigma_{i j}\left(x_{i}, t\right)=\lambda \hat{\sigma}_{i j}\left(x_{i}, t\right)+\bar{\rho}_{i j}\left(x_{i}\right)
$$

where $\bar{\rho}_{i j}$ denotes a constant residual stress field in equilibrium with zero surface tractions on $S_{T}$, which corresponds to the residual state of stress at the beginning and end of the cycle.

Based upon the kinematic theorem of Koiter [16] and Melan's lower bound shakedown theorem [17] the LMM procedure has proved to produce very accurate upper and lower bound shakedown limits [11] [17].

2.1 Upper Bound Procedure. Koiter's theorem states: For all Kinematically Admissible (KA) strain rate histories $\lambda_{U B} \int_{0 V}^{T} \int_{i j} \hat{\sigma}_{i j}(x, t) \dot{\varepsilon}_{i j}{ }^{c} d V d t=\int_{0 V}^{T} \int_{V} D\left(\dot{\varepsilon}_{i j}{ }^{c}\right) d V d t=\int_{0 V}^{T} \int_{V} \sigma_{i j}^{c} \dot{\varepsilon}_{i j}^{c} d V d t$ where $\sigma_{i j}^{c}$ denotes a state associated with $\dot{\varepsilon}_{i j}^{c}$ ( all strain rate histories that accumulate over a cycle) at yield. Then $\lambda_{U B} \geq \lambda_{s}$ where $\lambda_{s}$ is the shakedown limit. Koiter's theorem is also called upper bound shakedown theorem.

Theory [11] shows the form $\left(\lambda_{U B}^{f} \leq \lambda_{U B}^{i}\right)$ of the upper bound theorem that allows the LMM to be displayed as a programming method. [18] shows that the yield condition and the linear material provide the same stress for strain rate history at an initial KA $\dot{\varepsilon}_{i j}^{i}$. As a result the matching condition is:

$$
\sigma_{i j}^{L i}=\sigma_{i j}^{p i}
$$

where $\sigma_{i j}^{p i}$ is the associated stress at yield.

For the von Mises yield condition, matching condition (4) becomes:

$$
\mu=\frac{2 \sigma_{y}}{3 \overline{\dot{\varepsilon}}^{i}}
$$

Where $\overline{\dot{\varepsilon}}$ denotes the von Mises effective strain rate and $\mu$ denotes shear modulus. The upper bound multiplier can be obtained by a single iteration that begins with the evaluation of a varying shear modulus $\mu$ by matching the stress due to the linear model and the yield condition at the strain rate $\dot{\varepsilon}_{i j}^{i}$ yielded by the previous iteration. Each iteration provides both a kinematically admissible strain rate history and an equilibrium distribution of residual stress, while upper bounds are generated such that they converge to the minimum upper bound.

2.2 Lower Bound Procedure. Melan's theorem states: If a time constant residual stress field $\bar{\rho}$ exists such that superposition with induced elastic stresses $\lambda_{L B} \hat{\sigma}_{i j}(x, t)$ forms a safe state of stress everywhere in the structure, i.e.

$$
\begin{gathered}
f\left(\lambda_{L B} \hat{\sigma}_{i j}\left(x_{i}, t\right)+\bar{\rho}_{i j}\left(x_{i}\right)\right) \leq 0 \\
\lambda_{L B} \leq \lambda_{s}
\end{gathered}
$$

Melan's theorem can also be called lower bound shakedown theorem or static shakedown theorem. On the basis of Melan's lower bound shakedown theorem, a lower bound of shakedown limit can be constructed in the same procedure by maximising the lower bound load parameter $\lambda_{L B}$ under the condition where for any potentially active load/temperature path, the stresses resulting from the superposition of this constant residual stress field $\bar{\rho}_{i j}$ with the thermal-mechanical elastic stress $\lambda_{L B} \hat{\sigma}_{i j}$ nowhere violate the temperature-dependent yield condition. Hence, as the above upper bound iterative process provides a sequence of residual stress fields it is possible to evaluate a lower bound at each iteration by scaling the elastic solution so that $\lambda_{L B} \hat{\sigma}_{i j}+\bar{\rho}_{i j}$ everywhere satisfies yield. The lower bound of shakedown load multiplier can be written as: $\lambda_{L B}^{s}=\max \lambda_{L B}$

2.3 Iteration Steps of LMM Shakedown Analysis. A very significant advantage of the method comes from the 
ability to use standard commercial finite element codes which have the facility to allow the user to define the material behaviour. This has been done in the code ABAQUS with user subroutine UMAT. Essentially, ABAQUS carries out a conventional step by step analysis and, through the use of user routine, each increment is reinterpreted in terms of an iteration of the method. At each increment, the user routine UMAT allows a dynamic prescription of the Jacobian which defines the relationship between increments of stress and strain. Fig. 1 presents a flow chart showing the $i+1$ iteration steps in ABAQUS for estimating the shakedown limit using the upper and lower bound theorem. A detailed iteration for lower bound and upper bound shakedown limit is given in [17].

$$
\mu_{k}^{i+1}=\frac{\sigma_{y}}{\varepsilon_{k}^{i}}
$$

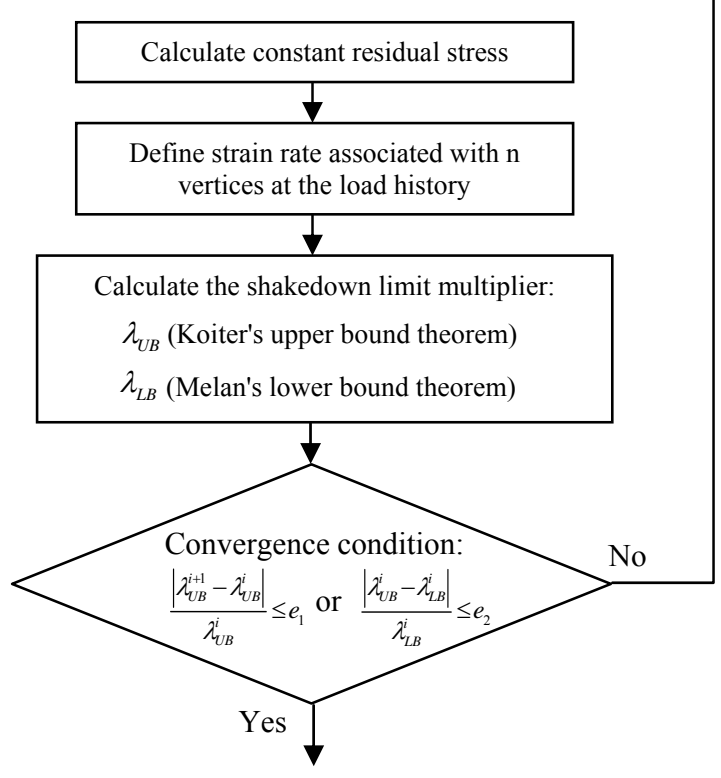

Fig. 1 LMM flow diagram for $\mathrm{i}+1$ iteration step

\section{COMPOSITE CYLINDER GEOMETRY}

The geometrical shape and the material properties of the composite cylinder with a cross hole are as shown in Fig. 2 and Table1, respectively. The composite thick cylinder has an inner layer of steel and an outer layer of aluminium. $R_{i}, R_{m}, R_{o}$ are the inner radius, middle radius, and outer radius of the composite cylinder, respectively.

The area surrounding the hole, which can be an instrumentation tapping or a port for the fluid entry or exit, is expected to be the most critical region since this is a structure discontinuity causing the rise of the local stress concentration. To improve the mechanical performance of this critical region, the material surrounding the hole is selected to be high performance steel. The thickness of this steel insert is equal to $\frac{R_{o}-R_{i}}{2}$.

The shakedown results are obtained for three different radius ratios: $\frac{R_{o}}{R_{i}}=1.5,1.75,2.0$.Three cross-hole radius ratios are modelled: $\frac{r_{i}}{R_{i}}=0.1,0.2,0.3$. The size of the steel insert in Fig. 2 remains constant for all $\frac{r_{i}}{R_{i}}$ ratios. The maximum radius ratios $\frac{r_{i}}{R_{i}}$ defined in this paper meet the requirement of ASME B\&PV Code Section VIII Division 2, in which the limitation of $\frac{r_{i}}{R_{i}}$ should be less or equal to $1 / 2$ for perforated cylindrical shells [19]. The analysis is performed for three composite material ratios: $\frac{V_{s}}{V_{A}}=\frac{1}{3}, 1,3$ Where $V_{s}$ and $V_{A}$ stands for the volume of steel and aluminium, respectively. For better result comparison, in all the cases the inner radius is chosen to be $R_{i}=300 \mathrm{~mm}$ while length is $L=900 \mathrm{~mm}$.
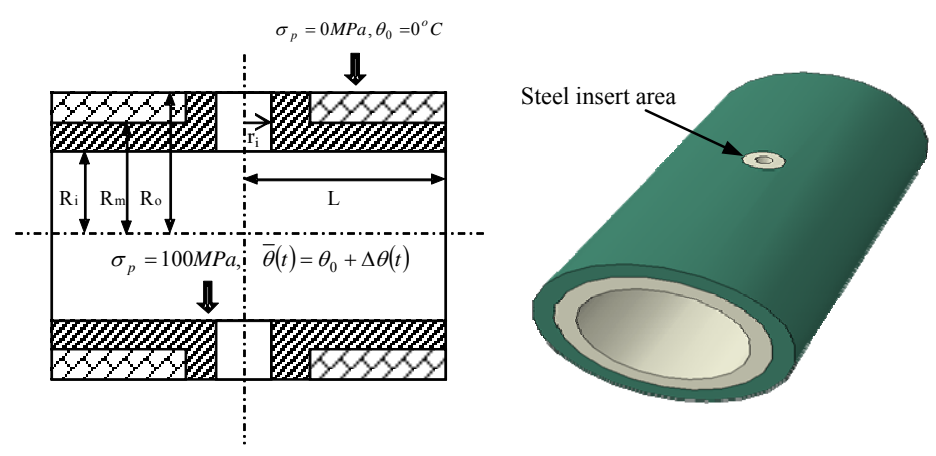

Fig. 2 Geometrical shape of composite cylinder 
Table 1 Material property parameters for the steel and aluminium

\begin{tabular}{|c|c|c|c|c|c|}
\hline Type & Young's modulus E (GPa) & $\begin{array}{c}\text { Poisson's } \\
\text { ratio } v\end{array}$ & $\begin{array}{c}\text { Coefficient of } \\
\text { thermal expansion } \alpha \\
\left({ }^{\circ} C^{-1}\right)\end{array}$ & $\begin{array}{c}\text { Yield stress } \\
\sigma_{\mathrm{y}}(\mathrm{MPa})\end{array}$ & $\begin{array}{c}\text { Thermal Conductivity } \\
\kappa-(\mathrm{W} / \mathrm{mK})\end{array}$ \\
\hline Steel & 200 & 0.3 & $1.4 \times 10^{5}$ & 360 & $\begin{array}{c}\text { Density } \\
\left(\mathrm{Kg} / \mathrm{mm}{ }^{3}\right)\end{array}$ \\
\hline Aluminium & 72 & 0.33 & $2.36 \times 10^{5}$ & 100 & 20 \\
\hline
\end{tabular}

\section{FINITE ELEMENT MODELLING}

The composite cylinders are analysed using ABAQUS type C3D20R 20 node quadratic brick elements with reduced integration scheme. The composite cylinders with cross-holes have three planes of symmetry. Hence, to minimize the size of the model, these symmetry boundary conditions are applied to a quarter model. A closer $3 \mathrm{D}$ view of a composite cylinder with cross-hole is shown in Fig. 3. The constant internal pressure is applied to the main cylinder bore and hole bore. The cut end of the cylinder is constrained such that the plane section remains plane during loading. The closed-end boundary condition is represented by applying a uniform axial thrust to the end of the cylinder. The holes are assumed to have open-ended boundary condition. The applied cyclic thermal loading is produced by assuming that the outside surface of the cylinder is at ambient temperature while the internal surface temperature is fluctuating from ambient to higher values. Three thermal stress extremes are used for this cyclic load history:

- Firstly, according to different thermal conductivities of the steel and aluminium, a thermal stress is produced by the most significant nonlinear thermal gradient along the thickness. This most significant thermal load is calculated by a steady-state thermal analysis,

- Secondly, a thermal stress occurring at the highest uniform temperature is applied due to the material mismatch. This thermal stress is adopted knowing that thermal expansions between the steel and aluminium are significantly different,

- Finally, a zero thermal stress field is selected to simulate a uniform ambient temperature for the whole cylinder.

When the ambient temperature $\theta_{0}$ remains at $0^{\circ} \mathrm{C}$, the magnitudes of the maximum von Mises effective thermo elastic stresses for the above thermal loading extremes can be determined by the maximum temperature difference $\Delta \theta$ between the inner surface and outer surface of the composite cylinder. Hence these thermal and mechanical load path extremes can be characterised by the internal pressure $\sigma_{p}$ and the maximum temperature difference $\Delta \theta$. The reference constant elastic mechanical stress can be calculated by the internal pressure $\sigma_{p}=\sigma_{p 0}=\sigma_{y}^{\text {aluminium }}=100 \mathrm{MPa}$ while the reference temperature difference $\Delta \theta=\Delta \theta_{0}=100^{\circ} \mathrm{C}$ determines the reference cyclic thermal elastic stresses. When the temperature-dependent yield stress $\sigma_{Y}(T)$ is adopted, the actual load factor is updated in an iterative way during the calculation. The adopted temperature-dependent yield stress is given in Equation (7) for steel and presented in Table 2 for aluminium;

$$
\sigma_{Y}(T)=\sigma_{Y}^{0}-0.4\left(\mathrm{MPa} /{ }^{\circ} \mathrm{C}\right) \times T
$$

Table 2 Temperature-dependent yield stress for aluminium

\begin{tabular}{|c|c|c|c|c|c|c|c|c|c|}
\hline Temperature $\left({ }^{\circ} \mathrm{C}\right)$ & 0 & 100 & 200 & 300 & 400 & 500 & 525 & 550 & 600 \\
& & & & & & & & & \\
\hline$\sigma_{y}(T)(\mathrm{MPa})$ & 100 & 90 & 72.7 & 43.9 & 31.8 & 27.3 & 23.2 & 19.3 & 15.1 \\
\hline
\end{tabular}

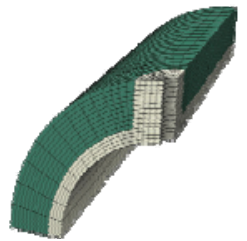

(a)

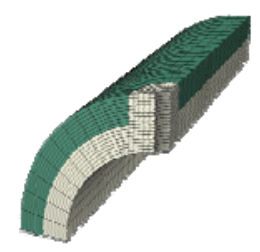

(b)

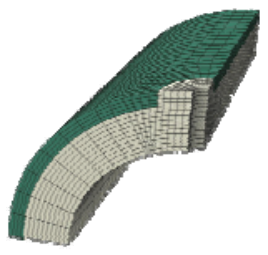

(c)
Fig. 3 Quarter finite element models for different material ratios

$$
\text { a) } \frac{V_{s}}{V_{A}}=\frac{1}{3} \text { b) } \frac{V_{s}}{V_{A}}=1 \text { c) } \frac{V_{s}}{V_{A}}=3
$$

\section{RESULTS AND DISCUSSIONS}

5.1 Upper and Lower Bound Results with Temperature Dependent and Independent Yield Stress. Based upon the kinematic theorem of Koiter [16], the LMM procedure has proved to produce highly accurate upper bound [11] and lower bound shakedown limits [17]. The converged values of both upper and lower bounds shakedown limits for the composite cylinder are shown in Fig. 4 where material radio $\frac{V_{s}}{V_{A}}=1$, $\frac{R_{O}}{R_{i}}=1.75, \frac{r_{i}}{R_{i}}=0.1$. An interaction diagram composed of the shakedown limit for different ratios of varying thermal load and constant mechanical load is also presented. This limit is divided into two regions; reverse plasticity limit $\mathrm{AB}$ or $\mathrm{A}^{*} \mathrm{~B}^{*}$, and ratchet limit $B C$ or $B^{*} C$. Shakedown will not occur when the applied load is beyond the reverse plasticity limit $A B / A * B *$, where the permanent strains settle into a closed cycle, a situation also known as "cyclic" or "alternating plasticity". These permanent plastic strains will increase indefinitely if the applied load is beyond the ratchet limit $\mathrm{BC} / \mathrm{B}^{*} \mathrm{C}$, a condition known as "ratchetting". The point $\mathrm{C}$ corresponds to the limit load for the applied mechanical load. There are significant differences between the reverse plasticity limit $A^{*} B^{*}$ adopting temperature-dependent yield stress and the reverse plasticity 
limit $\mathrm{AB}$ considering temperature-independent yield stress. It is important to adopt temperature-dependent yield stress for a structure assessment under high temperature variations. In order to simplify the calculations, the temperature-independent yield stress is adopted when the variation of operating temperature approaches to zero or the temperature varies within a limited range. The temperature effects on the yield stress may be ignored in such conditions.

Fig. 4b shows typical upper and lower bound sequences converging after 80 iterations for load point $\mathrm{A}$ (Fig. 4a)

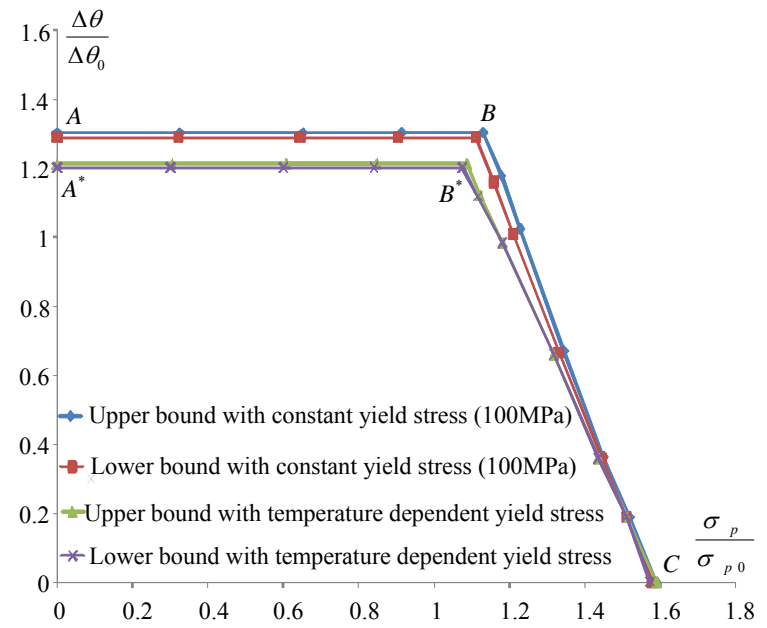

(a) considering temperature-independent yield stress, and for load point $A *$ (Fig. 4a) considering temperature-dependent yield stress. It can be observed that both the upper bound and lower bound converge to the exact shakedown limit proving that LMM produces highly accurate upper bound and lower bound shakedown limit results. For better view, the results obtained in the coming section are upper bound shakedown limit with temperature-independent yield stress.

Fig. 4 a) Upper and lower bounds shakedown limit interaction curves of the composite cylinder b) the convergence condition of iterative processes for shakedown analysis (point $\mathrm{A}$ and $\mathrm{A}^{*}$, subjected to changing thermal loads only) $\left(\frac{V_{s}}{V_{A}}=1, \frac{R_{O}}{R_{i}}=1.75, \frac{r_{i}}{R_{i}}=0.1\right)$

5.2 Effect of the composite material ratio. The shakedown interaction curves of a composite cylinder with varying material ratio configurations (Fig. 3) are presented in Fig. 5. The applied pressure in $\mathrm{X}$-axis is normalized with respect to the reference internal pressure and the thermal stress in $\mathrm{Y}$-axis is normalized by using the reference temperature difference $\Delta \theta=\Delta \theta_{0}=100^{\circ} \mathrm{C}$.

Fig. 5 shows that the limit load of the composite cylinder reduces when decreasing the volume of steel material whereas the reverse plasticity limit is increased with smaller $\frac{V_{s}}{V_{A}}$. The reduction in limit load is approximately in proportion to the loss of steel material. The increasing reverse plasticity limit is due to the difference in thermal conductivities of the steel and aluminium. As the volume of aluminium increases, more proportion of the cylinder has larger thermal conductivity, which leads to a lower thermal elastic stress range. Hence, when the volume of aluminium increases the reverse plasticity limit increases. Shakedown limit interaction curves of the composite cylinder $\left(\frac{R_{o}}{R_{i}}=1.5\right)$ with cross hole for different composite material ratios and different cross hole ratios are

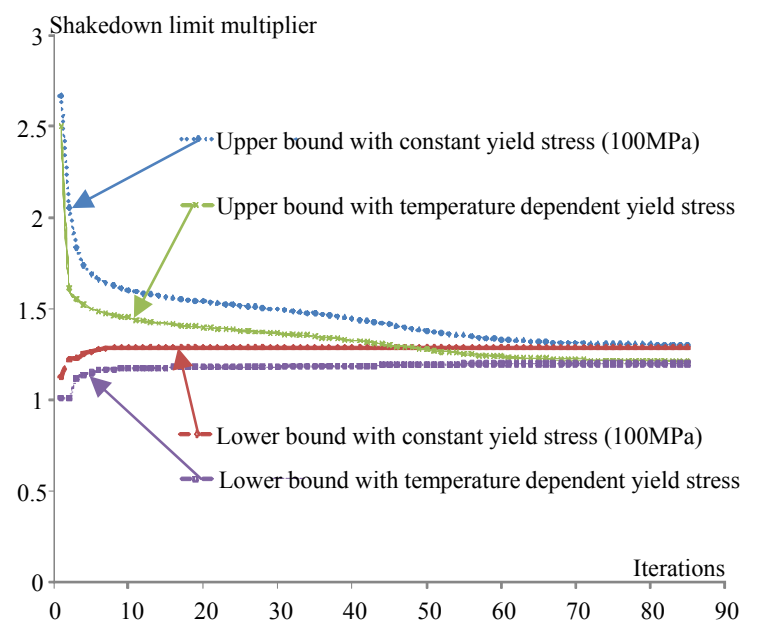

(b) presented in Fig. 6 which shows that with the addition of a cross hole, the general trend of the shakedown curves is similar to Fig. 5 - both show an decreasing limit load and increasing reverse plasticity limit for decreasing volume of steel. The addition of a hole gives rise to a local stress concentration. This is shown to have little effect on the limit load for any material configuration when hole diameter is smaller. A detailed discussion of the effects of the hole diameter is given in section 5.3.

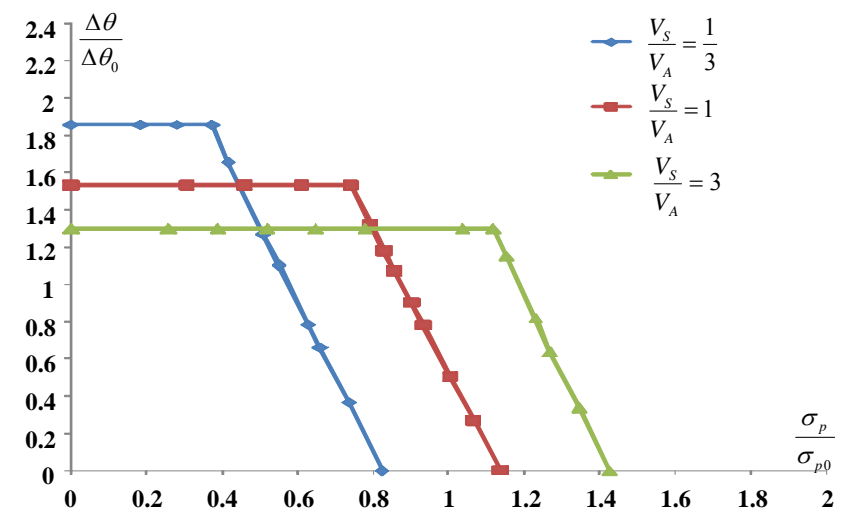

Fig. 5 Shakedown limit interaction curves of the composite cylinder for different composite material ratio without cross hole 


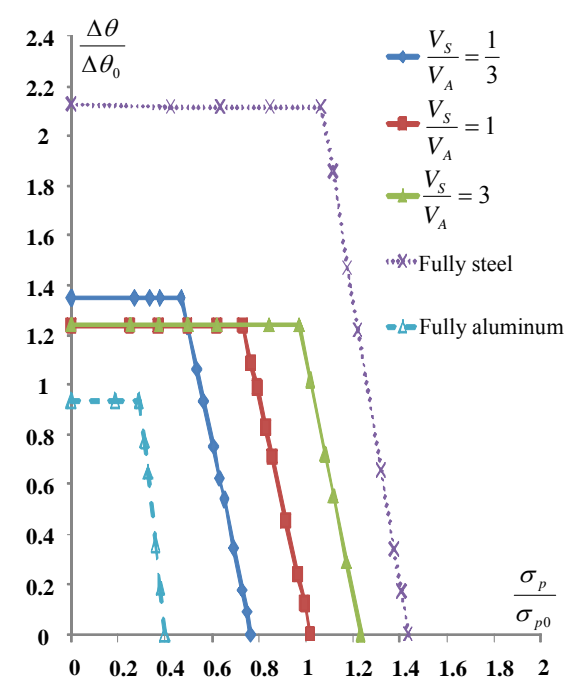

(a)

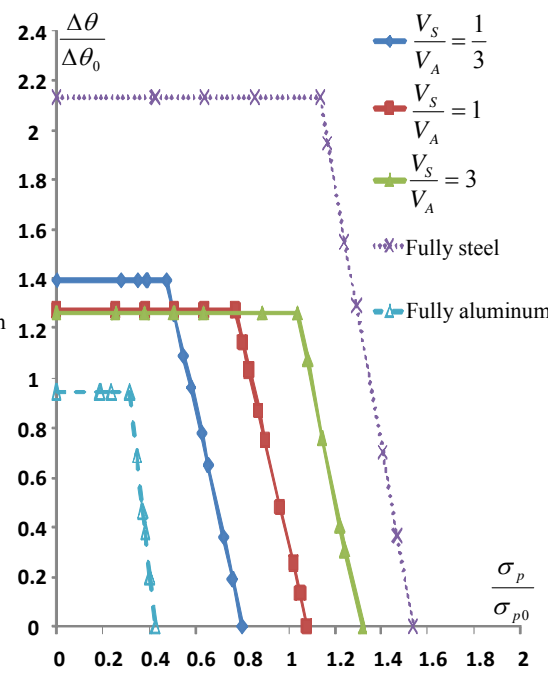

(b)

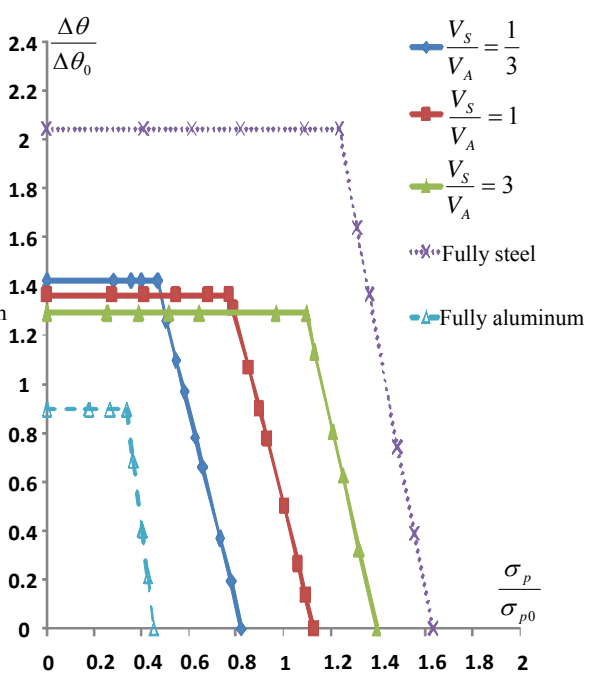

(c)

Fig. 6 Shakedown limit interaction curves of the composite cylinder $\left(\frac{R_{O}}{R_{i}}=1.5\right)$ for different composite material ratio with different cross hole

$$
\text { ratio: a) } \frac{r_{i}}{R_{i}}=0.3 \text { b) } \frac{r_{i}}{R_{i}}=0.2 \text { c) } \frac{r_{i}}{R_{i}}=0.1
$$

5.3 Effect of the Hole Diameter. Cross holes in composite cylinders are structural discontinuities which increase elastic stress due to local stress concentration. The influence of cross hole size, $\frac{r_{i}}{R_{i}}=0.1,0.2,0.3$ on the shakedown limit interaction curve is shown in Fig. 7 with different material ratio configurations.

Fig. 7a presents that for a material ratio of $\frac{1}{3}$, the addition of a hole has a large impact on the reverse plasticity limit, which shows the dominance of this stress raiser to the mechanism. The addition of a hole is shown to have negligible effect on the limit load. When the material ratio $\frac{V_{s}}{V_{A}}=\frac{1}{3}$, the limit load is determined by the large proportion of the aluminium material due to its low yield stress. The introduction of hole has much less effect on the limit load than this small material ratio.

Fig. $7 \mathrm{~b}$ shows that for a material ratio of 1 , the addition of a hole has a sizable effect on the reverse plasticity limit, but impacts the limit load less significantly than Fig. 7c for a material ratio of 3 . This is because when the material ratio reduces to 1 , the stress concentration from the hole becomes comparable with the stress concentration due to the material mismatch. When the size of hole increases, both the limit load and reverse plasticity limit decreases.
Fig. $7 \mathrm{c}$ shows that for a material ratio of 3 , the addition of a hole has little effect on the value of reverse plasticity limit, but causes a reduction in the limit load. The reduction in material caused by increasing hole diameter is the cause of the reduction in limit load. Little effect of the hole size on the reverse plasticity limit is due to the dominance of the material boundary stress raiser, which has little interaction with the stress concentration caused by the hole.

\subsection{Effect of the Composite Cylinder Thickness. Fig. 8} shows the effects of the radius ratio $\frac{R_{O}}{R_{i}}$ on the shakedown interaction curve. Three different relative thickness $\frac{R_{O}}{R_{i}}=1.5,1.75,2.0$ of composite cylinder with a fixed material ratio of 1 were analyzed.

Increasing the radius ratio greatly increases the limit load and reduces the reverse plasticity limit. The increase in limit load is an obvious result, as effectively the thickness of the pipe is increased for the same inner radius. The reverse plasticity limit reduction is caused by the increased thickness of steel. This increase in thickness (which causes greater conduction temperatures in the steel) results in higher thermal stresses at the material boundary. 


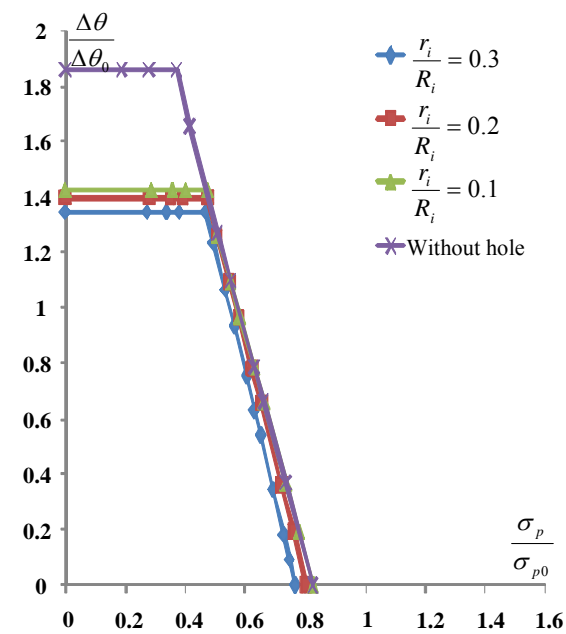

(a)

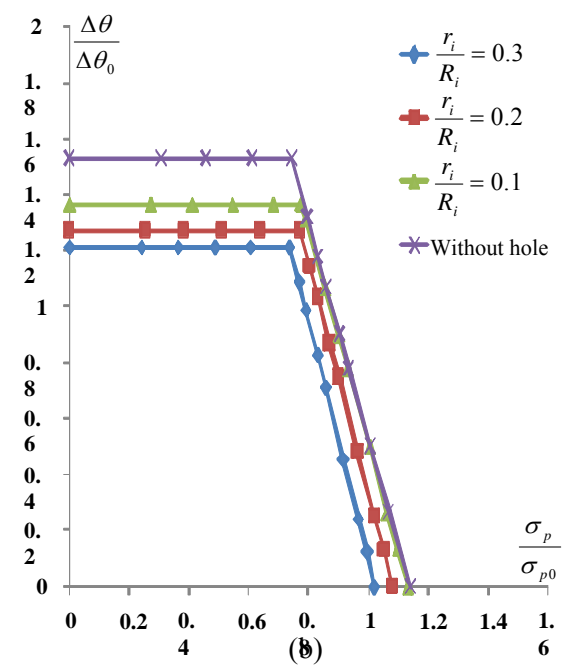

(B)

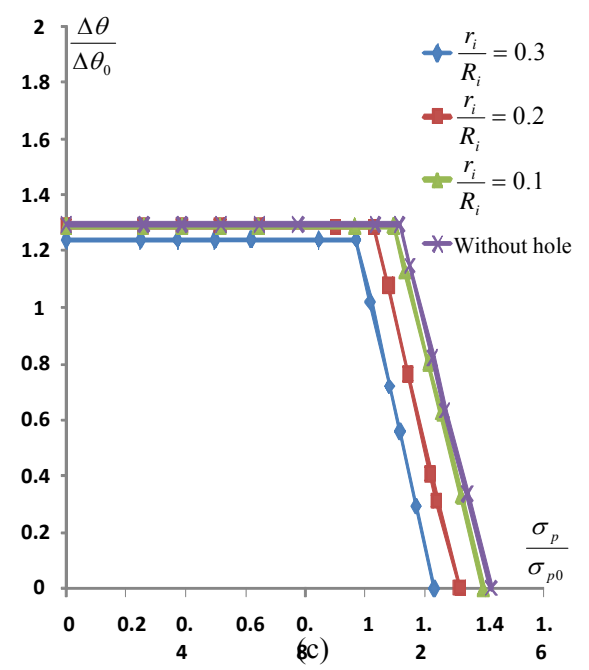

Fig. 7 Shakedown limit interaction curves of the composite cylinder $\left(\frac{R_{o}}{R_{i}}=1.5\right)$ with different hole radius ratios and different composite material ratios: a) $\frac{V_{s}}{V_{A}}=\frac{1}{3}$ b) $\frac{V_{s}}{V_{A}}=1$ c) $\frac{V_{s}}{V_{A}}=3$
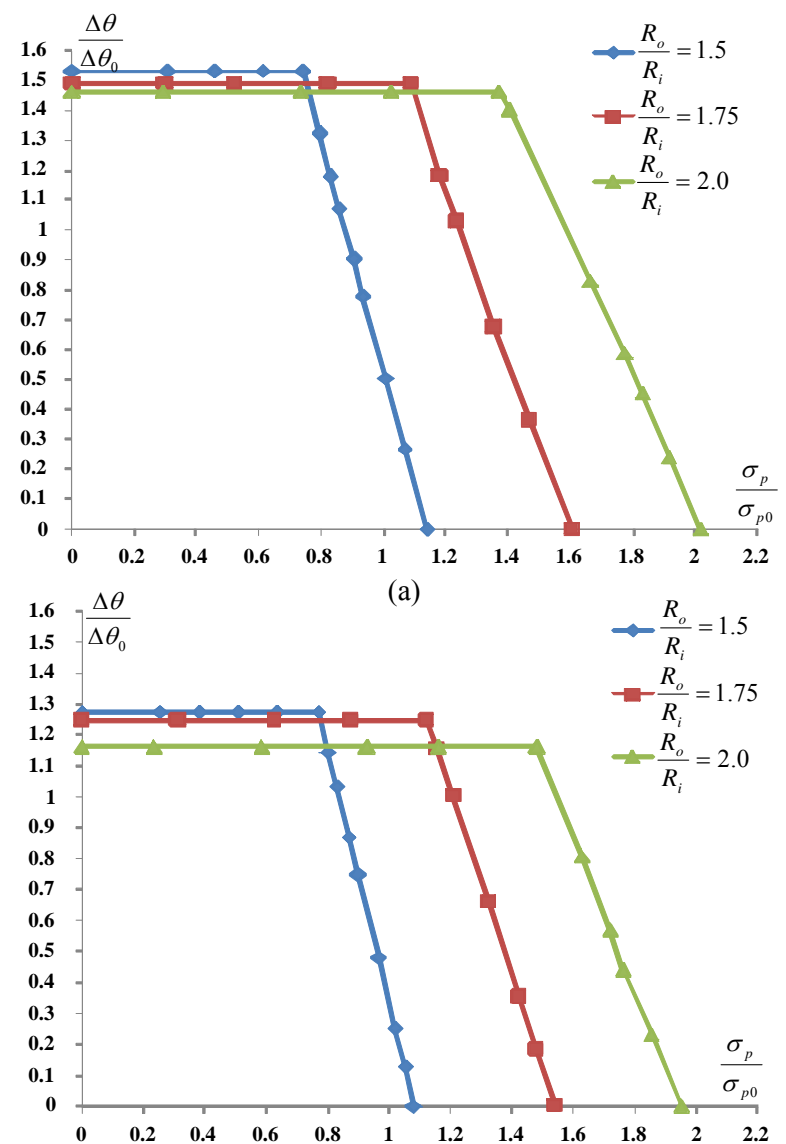

(c)

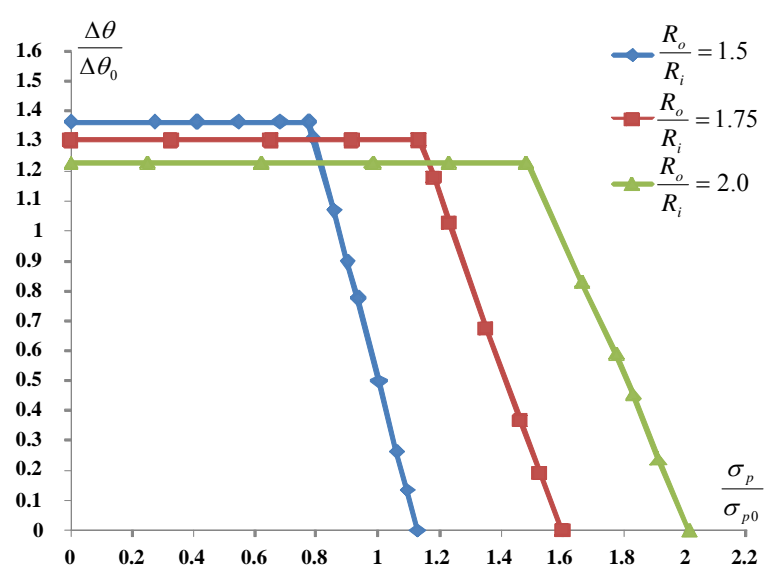

(b)

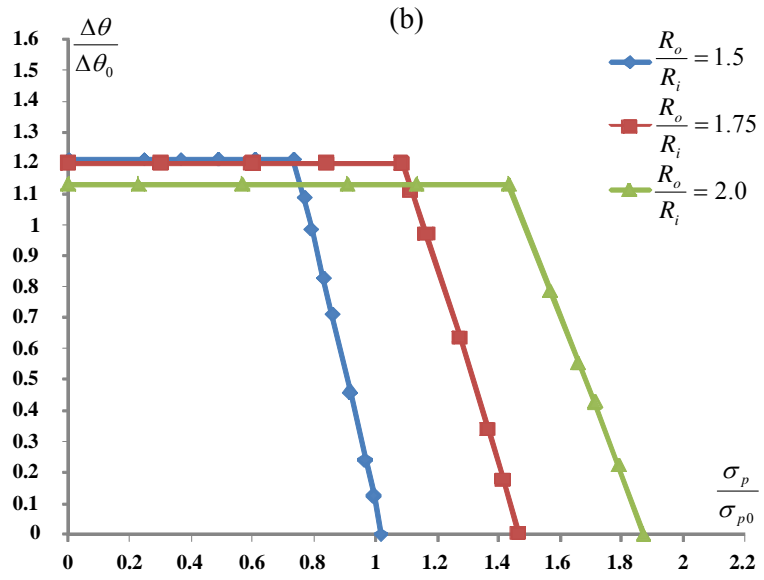

(d)

Fig. 8 Shakedown limit interaction curves for the composite cylinder $\left(\frac{V_{s}}{V_{A}}=1\right)$ with different thickness radius ratios and different hole radius ratios: a) without hole b) $\frac{r_{i}}{R_{i}}=0.1$ c) $\frac{r_{i}}{R_{i}}=0.2$ d) $\frac{r_{i}}{R_{i}}=0.3$ 
5.5 Formulated Shakedown Limit Design Region. An elastic shakedown limit formulation of the composite cylinder is made for the safety of engineering design. The elastic shakedown design regions of composite cylinders are shown in Fig. 9 Where $\Delta \theta_{R L}$ is the design temperature range corresponding to the reverse plasticity limit, $P_{R L}$ is the design internal pressure representing the limit load and $S_{R L}$ is the design slope of the ratchet limit curve. To simplify, $\Delta \theta_{R L}$ and $P_{R L}$ are assumed to be the product of three independent function $f_{1}\left(\frac{r_{i}}{R_{i}}\right), f_{2}\left(\frac{V_{S}}{V_{A}}\right), f_{3}\left(\frac{R_{o}}{R_{i}}\right)$ and $g_{1}\left(\frac{r_{i}}{R_{i}}\right)$, $g_{2}\left(\frac{V_{S}}{V_{A}}\right), g_{3}\left(\frac{R_{o}}{R_{i}}\right)$, respectively. The applied pressure in the $\mathrm{X}$ direction is normalized with respect to $P_{R L}$ and the applied temperature difference in $\mathrm{Y}$ direction is normalized with respect to $\Delta \theta_{R L}$. Therefore, the design shakedown limits are formulated as,

$$
\begin{aligned}
& \Delta \theta_{R L}=\Delta \theta_{L} f_{1}\left(\frac{r_{i}}{R_{i}}\right) f_{2}\left(\frac{V_{S}}{V_{A}}\right) f_{3}\left(\frac{R_{o}}{R_{i}}\right) \\
& P_{R L}=P_{L} g_{1}\left(\frac{r_{i}}{R_{i}}\right) g_{2}\left(\frac{V_{S}}{V_{A}}\right) g_{3}\left(\frac{R_{o}}{R_{i}}\right) \\
& S_{R L}=75^{\circ}
\end{aligned}
$$

Where $f_{1}\left(\frac{r_{i}}{R_{i}}\right), f_{2}\left(\frac{V_{S}}{V_{A}}\right), f_{3}\left(\frac{R_{o}}{R_{i}}\right)$, are the influence functions for the design temperature range corresponding to the reverse plasticity limit and $g_{1}\left(\frac{r_{i}}{R_{i}}\right), g_{2}\left(\frac{V_{S}}{V_{A}}\right), g_{3}\left(\frac{R_{o}}{R_{i}}\right)$ are the influence functions for the design internal pressure representing the limit load. $\frac{r_{i}}{R_{i}}, \frac{V_{S}}{V_{A}}$ and $\frac{R_{o}}{R_{i}}$ stands for the cross-hole ratio, steel to aluminium ratio and thickness ratio, respectively.

$\Delta \theta_{L}$ and $P_{L}$ are constants standing for the calculated reverse plasticity limit and the limit internal pressure in case of $\frac{R_{o}}{R_{i}}=1.5, \frac{V_{S}}{V_{A}}=1$ without cross hole, where,

$$
\begin{gathered}
\Delta \theta_{L}=153^{\circ} \mathrm{C} \\
P_{L}=113.8 \mathrm{MPa}
\end{gathered}
$$

Since the shakedown slope limit $S_{R L}$ obtained for the composite cylinder has similar values for different cases. Thus, for conservative reasons, the lowest slope limit $\left(S_{R L}=75^{\circ}\right)$ is selected as a reference slope limit.

In order to find these influence functions, the obtained reverse plastic limits and internal pressure limit are normalised and replotted in graphs of functions $\mathrm{f}$ and $\mathrm{g}$ against $\frac{r_{i}}{R_{i}}, \frac{V_{S}}{V_{A}}$ and $\frac{R_{o}}{R_{i}}$ respectively as shown in Fig. 10 and Fig. 11. Trend lines are fit to the data obtained from the shakedown limit results of different composite material ratio and cylinder thickness ratio with different cross-hole sizes to show the influence function.

Equations (12a-12c) and Equations (13a-13c) are the obtained influence functions for the design temperature range corresponding to the reverse plasticity limit and for the design internal pressure representing the limit load, respectively. Once $\Delta \theta_{R L}$ the design temperature range corresponding to the reverse plasticity limit and $P_{R L}$ the design internal pressure representing the limit load are defined a safety shakedown envelope is created as shown in Fig. 9.

$$
\begin{aligned}
& f_{1}\left(\frac{r_{i}}{R_{i}}\right)= \begin{cases}1 & \left(\frac{r_{i}}{R_{i}}=0\right) \\
-0.411\left(\frac{r_{i}}{R_{i}}\right)+0.926 & \left(0.1 \leq \frac{r_{i}}{R_{i}}<0.3\right) \\
0.803 & \left(0.3 \leq \frac{r_{i}}{R_{i}}<0.7\right)\end{cases} \\
& f_{2}\left(\frac{V_{S}}{V_{A}}\right)=\left\{\begin{array}{lr}
0.659 & \text { (pure aluminium) } \\
0.015\left(\frac{V_{S}}{V_{A}}\right)^{2}-0.087\left(\frac{V_{S}}{V_{A}}\right)+1.072\left(\frac{1}{3} \leq \frac{V_{S}}{V_{A}} \leq 3\right) \\
1.495 & \text { (pure steel) }
\end{array}\right. \\
& f_{3}\left(\frac{R_{o}}{R_{i}}\right)=-0.659\left(\frac{R_{o}}{R_{i}}\right)+1.989 \quad\left(1.5 \leq \frac{R_{o}}{R_{i}} \leq 2.25\right) \\
& \begin{cases}1 & \left(\frac{r_{i}}{R_{i}}=0\right)\end{cases} \\
& g_{1}\left(\frac{r_{i}}{R_{i}}\right)=\left\{\begin{array}{lc}
-0.494\left(\frac{r_{i}}{R_{i}}\right)+1.043 & \left(0.1 \leq \frac{r_{i}}{R_{i}}<0.3\right) \\
-0.872\left(\frac{r_{i}}{R_{i}}\right)+1.156 & \left(0.3 \leq \frac{r_{i}}{R_{i}}<0.7\right)
\end{array}\right. \\
& g_{2}\left(\frac{V_{S}}{V_{A}}\right)=\left\{\begin{array}{lc}
0.402 & (\text { pure } \text { aluminium } \\
0.173\left(\frac{V_{S}}{V_{A}}\right)+0.827 & \left(\frac{1}{3} \leq \frac{V_{S}}{V_{A}} \leq 3\right) \\
1.433 & \text { (pure steel })
\end{array}\right. \\
& g_{3}\left(\frac{R_{o}}{R_{i}}\right)=1.227\left(\frac{R_{o}}{R_{i}}\right)-0.84 \quad\left(1.5 \leq \frac{R_{o}}{R_{i}} \leq 2.25\right)
\end{aligned}
$$

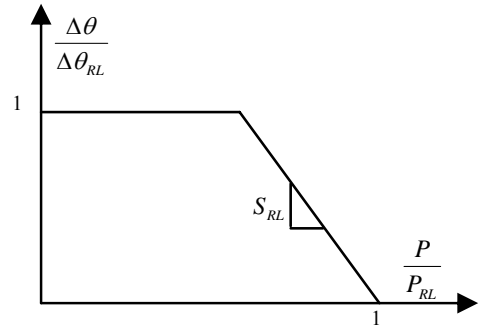




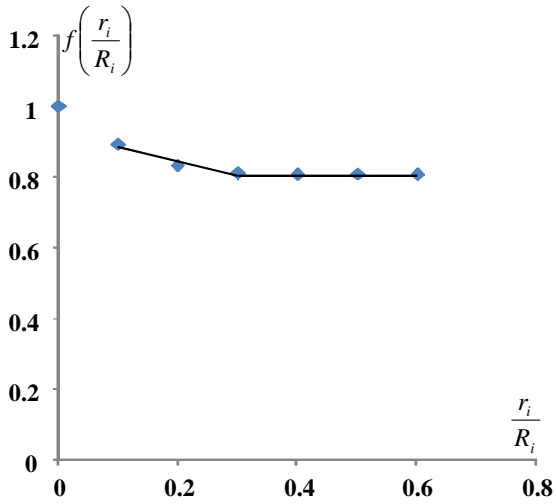

(a)

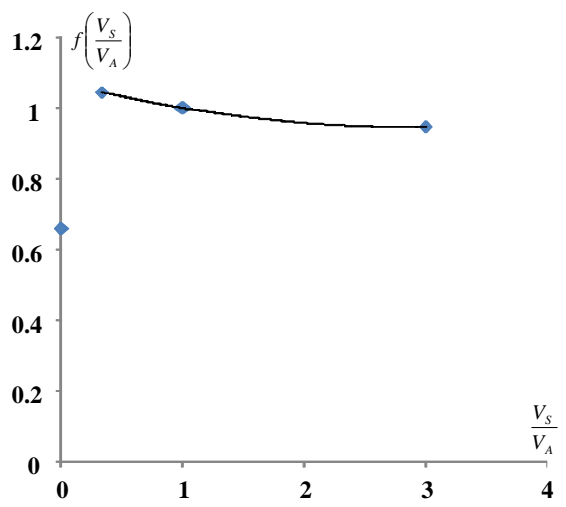

(b)

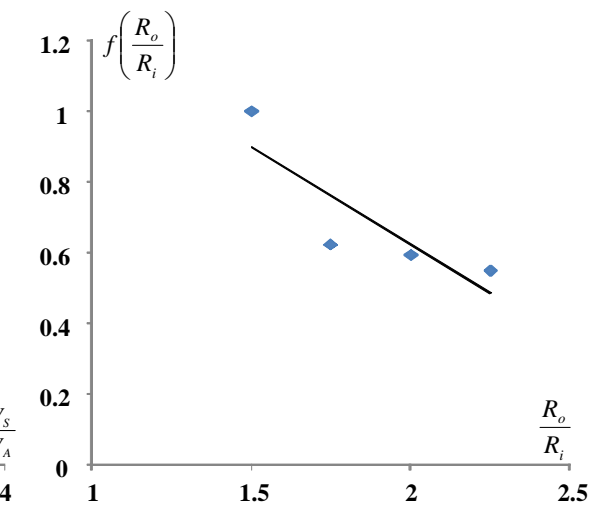

(c)

Fig. 10 Influence functions for reverse plasticity limits against: a) cross-hole ratio b) steel to aluminium ratio c) thickness ratio

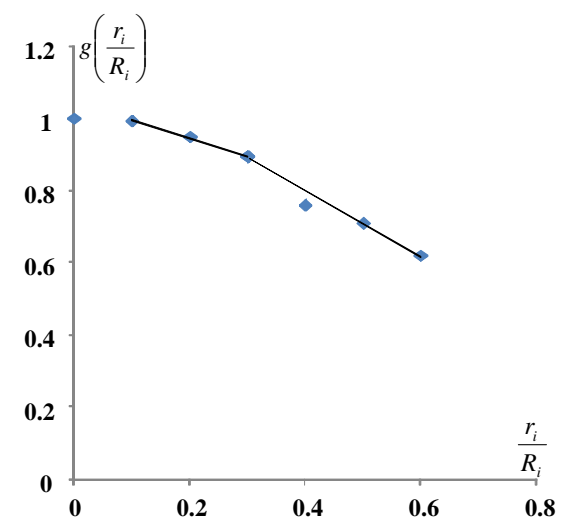

(a)

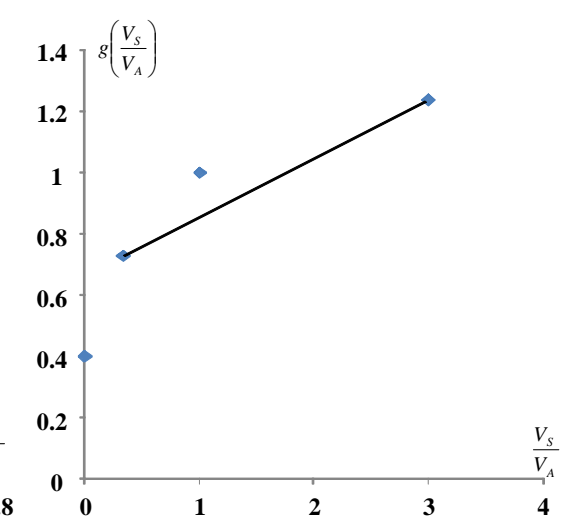

(b)

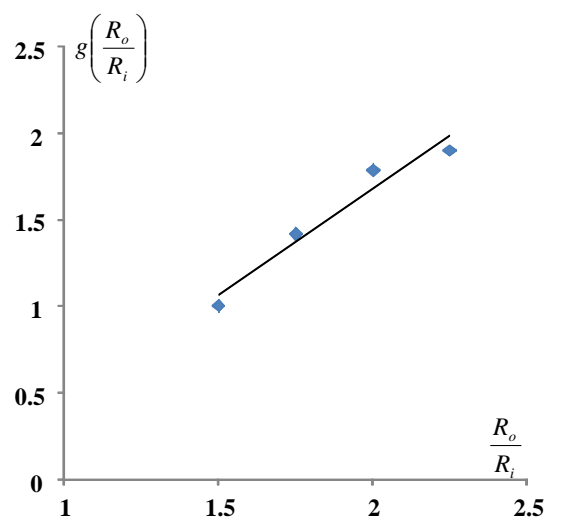

(c)

Fig. 11 Influence functions for limit pressures against: a) cross-hole ratio b) steel to aluminium ratio c) thickness ratio

\section{CONCLUSION}

The result obtained for the composite cylinder without cross-hole shows that the limit load decreases with the reduction of the steel material, whereas the reverse plasticity limit increases with the decreasing volume of steel. With the cross-hole addition, the general trend of the shakedown curves is similar to the one without cross hole - a decreasing limit load and increasing reverse plasticity limit for decreasing volume of steel. For steel to aluminium ratio $\frac{V_{s}}{V_{A}}=3$, the existence of a hole has little effect on the value of reverse plasticity limit, but it causes a reduction in the limit load. For material ratio of 1 , the existence of a hole has a sizable effect on the reverse plasticity limit, but impacts the limit load less significantly than for a material ratio of 3. For a material ratio $\frac{V_{s}}{V_{A}}=\frac{1}{3}$, the hole is shown to have negligible effect on the limit load. This implies that the size of the cross-hole raised the local stress concentration which will influence the fatigue life but will not greatly affect the global response when the limit load is determined by the low yield stress of the dominant aluminium material. Increasing the radius ratio highly increases the limit load and reduces the reverse plasticity limit. A safety shakedown envelope is created by formulating the shakedown limit results of different composite material and cylinder thickness ratios with different cross-hole sizes. In order to better understand the elastic-plastic response of the composite cylinder with cross-hole, further investigation and a parametric study are required for wider range of cross hole diameters and more variety of material ratios.

\section{ACKNOWLEDGEMENTS}

The authors gratefully acknowledge the support of the Engineering and Physical Sciences Research Council of the United Kingdom, and the University of Strathclyde during the course of this work. 


\section{REFERENCES}

1. Noor, Ahmed K., 2000, "Structures technology for future aerospace systems," Computers and Structures, 74, pp.507519

2. Thuis, H.G.S.J., \& Biemans, C., 1997,"Design fabrication and testing of a composite braket for aerospace applications,"Composite Structures, 38, pp. 91-98

3. Makulsawatudom, P., Mackenzie, D., and Hamiton, R., 2004, "Shakedown behaviour of thick cylindrical vessels with cross holes," Proc. Instn Mech. Engrs, 218, Part E: J. Process Mechanical Engineering

4. Camilleri, D., Mackemzie, D., Hamilton, R., 2009, "Shakedown of a Thick Cylinder With a Radial Crosshole," Journal of Pressure Vessel Technology 131(1), 011203-1

5. Liu YH, Carvelli V, Maier G., 1997, “Integrity assessment of defective pressurized pipelines by direct simplified methods". International Journal of Pressure Vessels and Piping, 74, pp.49-57

6. Vu, D.K., Yan, A.M., Nguyen-Dang, H., 2004, “A primaldual algorithm for shakedown analysis of structures". Comput. Methods Appl. Mech. Eng, 193, pp.4663-4674

7. Staat M., Heitzer M., 2001, "LISA a European Project for FEM-based Limit and Shakedown Analysis", Nuclear Engineering and Design, 206, pp.151-166.

8. Seshadri, R., 1995, "Inelastic Evaluation of Mechanical and Structural components Using the Generalized Local Stress Strain Method of Analysis", Nucl. Eng. Des., 153, pp.287-303

9. Mackenzie, D., Boyle, J. T., Hamilton, and R. \& Shi, J., 1996, "Elastic compensation method in shell-based design by analysis," Proceedings of the 1996 ASME Pressure Vessels and Piping Conference, 338, pp. 203-208

10. Mackenzie, D., Boyle, J.T., Hamilton, R., 2000, "The elastic compensation method for limit and shakedown analysis: a review," Trans IMechE, Journal of Strain Analysis for Engineering Design, 35, pp.171-188

11. Chen, H.F., Ponter ARS., 2001, "Shakedown and limit analyses for 3-D structures using the Linear Matching Method", International Journal of Pressure Vessels and Piping, 78, pp.443-451.

12. Chen, H.F. and Ponter, A.R.S., 2001, "A Method for the Evaluation of a Ratchet Limit and the Amplitude of Plastic Strain for Bodies Subjected to Cyclic Loading”, European Journal of Mechanics, A/Solids, 20 (4), pp.555-571

13. Chen, H.F., Ponter, A.R.S and Ainsworth, R.A., 2006, "The Linear Matching Method applied to the High Temperature Life Integrity of Structures, Part 1: Assessments involving Constant Residual Stress Fields", International Journal of Pressure Vessels and Piping, 83(2), pp.123-135
14. Chen, H.F., Ponter, A.R.S and Ainsworth, R. A., 2006, "The Linear Matching Method applied to the High Temperature Life Integrity of Structures, Part 2: Assessments beyond shakedown involving Changing Residual Stress Fields", International Journal of Pressure Vessels and Piping, 83(2), pp.136-147

15. Chen, H.F. \& Ponter, A.R.S., 2006, "Linear Matching Method on the evaluation of plastic and creep behaviours for bodies subjected to cyclic thermal and mechanical loading", International Journal for Numerical Methods in Engineering, 68, pp.13-32

16. Koiter W T, 1960, "General theorems for elastic plastic solids," Progress in solid mechanics J.N.Sneddon and R.Hill, eds. North Holland, Amsterdam, 1, pp.167-221

17. Chen, H.F., 2010, "Lower and Upper Bound Shakedown Analysis of structures With Temperature-Dependent Yield Stress", Journal of Pressure Vessel Technology, 132(1), 011202-1

18. Ponter, A.R.S. \& Chen, H.F., 2001, “A minimum theorem for cyclic load in excess of shakedown, with application to the evaluation of a ratchet limit," European Journal of Mechanics - A/Solids , 20, pp.539-553

19. ASME, 2007, Boiler and Pressure Vessel Code, The American Society of Mechanical Engineers, New York.

20. Chen, H.F. \& Ponter, A.R.S., 2009, "Structural integrity assessment of super heater outlet penetration tube plate," International Journal of Pressure Vessels and Piping, 86, 412-419 